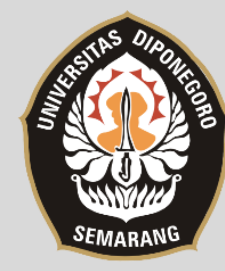

pISSN : $1829-8370$ eISSN : 2301-9069

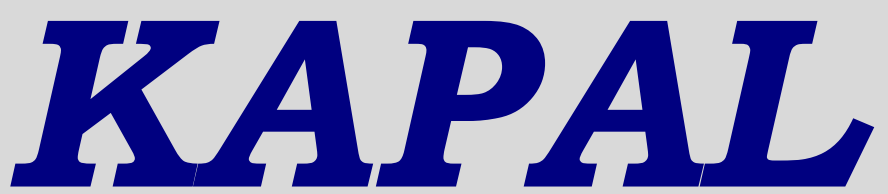

JURNAL ILMU PENGETAHUAN \& TEKNOLOGI KELAUTAN

\title{
Validasi Gerakan Benda Terapung Menggunakan Metode Smoothed Particle Hydrodynamics
}

\author{
Andi Trimulyono $* 1,2)$ \\ 1) Doctoral Student of Graduate School of Maritime Sciences, Faculty of Maritime Sciences, \\ Kobe University \\ ${ }^{2)}$ Departemen Teknik Perkapalan, Fakultas Teknik, Universitas Diponegoro \\ Jl. Prof. Soedarto, SH, Kampus Undip Tembalang, Semarang, Indonesia 50275
}

disubmit pada $: 25 / 02 / 18 \quad$ direvisi pada $: 17 / 04 / 18 \quad$ diterima pada $: 08 / 05 / 18$

\begin{abstract}
Abstrak
Pemodelan numerik menggunakan dinamika fluida komputasi(CFD) telah banyak digunakan untuk permasalahan teknik baik di bidang perkapalan maupun di kelautan secara umum. Interaksi fluida dan struktur merupakan salah satu topik yang menantang di bidang teknik. Pada artikel ini studi mengenai interaksi fluida benda terapung dilakukan menggunakan metode CFD berbasis Smoothed Particle Hydrodynamics(SPH) menggunakan DualSPHysics ver 4.0 yang merupakan open source solver SPH berbasis Weakly Compressible Smoothed Particle Hydrodynamics(WCSPH). Artikel ini membawakan validasi interaksi fluida dan struktur menggunakan CFD berbasis SPH dimana data eksperimen hasil dari penelitian sebelumnya. Berkat teknologi General Processing computation on Graphic Processing Unit (GPGPU) komputasi numerik menjadi lebih cepat dan pada studi ini komputasi numerik dilakukan menggunakan Graphic Processing Unit(GPU) GTX Titan. Analisa gerakan benda dilakukan hanya untuk dua dimensi dan gerakan benda terapung heave, surge dan pitch divalidasi menggunakan data eksperimen untuk tiga gerakan yang sama. Studi ini juga melakukan validasi gelombang hasil dari simulasi numerik SPH dengan eksperimen untuk dua posisi yang berbeda sebelum dan sesudah benda terapung. Berdasarkan hasil numerik SPH menunjukkan bahwa gerakan benda baik translasi maupun rotasi memiliki akurasi yang baik bila dibandingkan dengan hasil eksperimen ini diperlihatkan dari gerakan benda terapung baik translasi mapun rotasi hasil SPH memiliki hasil yang sama dengan eksperimen. Dengan hasil ini menunjukkan SPH memiliki akurasi yang cukup baik untuk permasalahan interaksi fluida apung meskipun metode ini tergolong masih baru.
\end{abstract}

Copyright $\odot$ 2018, KAPAL, pISSN:1829-8370, eISSN : 2301-9069

Kata Kunci : $C F D, S P H, W C S P H, G P G P U, G P U$

\section{PENDAHULUAN}

Pemodelan numerik menggunakan dinamika fluida komputasi $(C F D)$ telah banyak digunakan untuk permasalahan teknik baik di bidang perkapalan maupun di kelautan secara umum. Salah satu topik yang menantang di bidang kelautan adalah mengenai interaksi fluida dan struktur $(F S I)$. Pada permasalahan kali ini adalah

*) Penulis Korespondensi:

Email : anditrimulyono@gmail.com interaksi fluida dan struktur terapung. Banyak metode telah digunakan untuk permasalahan ini, pada artikel ini metode Smoothed Particle Hydrodynamics $(\mathrm{SPH})$ digunakan untuk menyelesaikan permasalahan interaksi fluida dan struktur terapung baik dari gerak translasi maupun rotasi seperti surge, heave maupun pitch.

Smoothed Particle Hydrodynamics (SPH) merupakan metode yang digunakan pertama kali untuk permasalahan mengenai astrofisika [1] Seiring perkembangannya $S P H$ dikembangkan 
untuk permasalahan mengenai free-surface [2]. SPH memiliki keunggulan dibanding metode mesh diantaranya tidak perlunya grid khusus dalam pemodelan. Karena tidak adanya grid pada pemodelan numerik cukup mendefinisikan jarak partikel pada kondisi awal membuat metode ini membutuhkan waktu yang lebih cepat dibanding metode mesh. Pemodelan menggunakan SPH untuk masalah gelombang telah banyak dilakukan oleh peneliti di dunia untuk bidang teknik pantai [3-7] menunjukkan hasil yang bagus dan telah memiliki akurasi yang baik serta telah tervalidasi dengan hasil eksperimen.

Hasil dari SPH untuk permasalahan gelombang menunjukkan potensi untuk aplikasi bidang teknik secara umum. Salah satunya adalah interaksi fluida dan struktur terapung merupakan salah satu topik menantang di bidang kelautan. Tujuan dari studi ini adalah analisa interaksi fluida dan struktur terapung menggunakan SPH dimana penelitian sebelumnya telah dilakukan oleh Hadz ic.et al [8]. Pada penelitian sebelumnya metode CFD mesh yang digunakan menunjukkan akurasi yang baik yang mana hasilnya telah divalidasi dengan eksperimen. Pada artikel ini akan membawakan penggunaan $C F D$ berbasis partikel yaitu $S P H$ untuk permasalahan yang sama. DualSPHysics ver. 4.0 [ 9] digunakan pada studi ini, DualSPHysics merupakan open source solver berbasis Weakly Compressible Smoothed Particle Hydrodynamics (WCSPH) yang dikembangkan dari SPHysics. DualSPHysics telah di kembangkan untuk dapat digunakan baik menggunakan Central Processing Units(CPU) maupun Graphic Processing Units(GPU). Dengan teknologi General Processing computation on Graphic Processing Unit(GPGPU) waktu komputasi dapat lebih cepat 2 kali dibandingkan menggunakan CPU [10]. Semua komputasi numerik $S P H$ pada studi ini dilakukan menggunakan GPU.

\section{METODE}

DualSPHysics merupakan $C F D$ berbasis partikel yang dikembangkan oleh universitas Manchester Inggris dan Universitas De Vigo Spanyol. Keunggulan dari penggunaan SPH untuk FSI adalah lebih mudah untuk permasalahan violent flow seperti interaksi gelombang dengan struktur terapung seperti seakeeping pada bidang perkapalan, interaksi kapal dengan gelombang maupun interaksi bangunan lepas pantai dengan gelombang dan aplikasi di bidang lainnya. Keunggulan metode ini juga adalah tidak perlunya mendefiniskan secara khusus kondisi free surface dikarenakan partikel telah membawa properti seperti densitas untuk mendefinisikan fluida.

Metode partikel merupakan metode $C F D$ yang mendiskritasi domain fluida dengan titik atau partikel dimana tiap partikel telah membawa properti masing-masing seperti massa, densitas, posisi partikel. Metode ini menggunakan metode interpolasi dimana tiap partikel dihitung berdasarkan properti partikel di sekitarnya menggunakan smoothing length untuk lebih jelasnya mengenai dasar teori maupun manual guide dari DualSPHysics dapat merujuk pada artikel Crespo et al [9].

Gambar 1. merupakan pemodelan numerik pada $S P H$ dimana untuk menghindari gelombang pantul maka domain fluida dibuat sepanjang 25.0 m. Posisi kotak sama seperti kasus yang digunakan oleh Hadz ic et al [8] yaitu $2.11 \mathrm{~m}$ di depan pembangkit gelombang (wavemaker). Perbedaan mendasar antara studi terdahulu adalah penggunaan $\mathrm{SPH}$ pada kasus ini, $\mathrm{Hadz}^{\circ}$ ic et al [8] menggunakan metode mesh yang akurasinya cukup baik. Pembangkit gelombang yang digunakan adalah tipe flap wavemaker dimana diletakan wave probe sensor pada posisi $1.16 \mathrm{~m}$ dan $2.66 \mathrm{~m}$ di depan pembangkit gelombang untuk digunakan memvalidasi gelombang dari $S P H$ dan eksperimen.

Simulasi numerik $S P H$ pada artikel ini menggunakan GPU GeForce GTX TITAN. Jarak awal partikel yang digunakan adalah $2.0 \mathrm{~mm}$ dan total partikel adalah 602.920. Total waktu yang diperlukan untuk waktu simulasi $15.0 \mathrm{~s}$ adalah 5.57 jam. Parameter yang digunakan di DualSPHysics ditunjukkan pada Tabel 1. Dimana untuk efek disipasi pada $S P H$ menggunakan artificial viscosity dengan nilai $\alpha=0.01$ dan untuk mereduksi osilasi dari densitas menggunakan $\delta$ $S P H$ dengan nilai 0.1 dan kedalaman air adalah $0.4 \mathrm{~m}$. Untuk benda terapung diberikan input massa relative weight 0.68

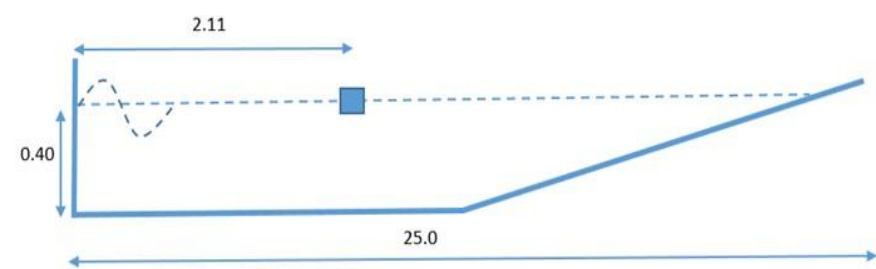

Gambar 1. Domain pada model numerik dengan

\section{1. Kondisi Batas} DualSPHysics

Kondisi batas pada DualSPHysics digambarkan sebagai satu set partikel terpisah dari partikel fluida dalam hal ini seperti dinding tanki, benda mengapung. Kondisi batas masih menjadi salah satu kekurangan metode ini karena tidak 
dimungkinkanya memberikan kondisi batas seperti no slip atau free slip.

DualSPHysics menggunakan metode Dynamic Boundary Condition (DBC) [11] dimana pada kondisi ini boundary particles memiliki properties yang sama dengan fluid particles namun boundary particles tetap diam dan tidak bergerak meski ada gaya yang bekerja. Partikel ini akan bergerak bila diberikan kondisi tertentu untuk bergerak sesuai gerakan yang diinginkan, kasus ini seperti wavemaker. Selain itu dimungkinkan juga kondisi batas dimana benda bergerak akibat dari gaya yang bekerja pada boundary particles (fluiddriven objects). Pada boundary particles ini gaya total pada setiap partikel dihitung berdasarkan penjumlahan kontribusi dari partikel fluida sekitarnya sesuai dengan kernel function and smoothing length. Untuk persamaan gerak benda didapatkan dari persamaan 1 dan persamaan 2

$M \frac{d V}{d t}=\sum_{k \in B^{P}} m_{k} f_{k}$

$M \frac{d \Omega}{d t}=\sum_{k \in B^{P_{s}}} m_{k}\left(r_{k}-R_{0}\right) \times f_{k}$

Dimana $\mathrm{M}$ adalah massa, I adalah moment inersia, $\mathrm{V}$ adalah kecepatan translasi, $\Omega$ kecepatan rotasi, $\mathrm{R}_{0}$ adalah pusat massa.

Tabel 1. Tabel parameter pada DualSPHysics

\begin{tabular}{lc}
\hline \multicolumn{2}{c}{ Parameter pada DualSPHysics } \\
\hline Kernel function & Wendland \\
Time step algorithm & Sympletic \\
Viscosity treatment & Artificial \\
Coefsound & 15 \\
Particle size $(\mathrm{mm})$ & 2 \\
Coefh & 1.2 \\
CFL number & 0.2 \\
$\delta$-SPH & 0.1 \\
Duration of simulation $(s)$ & 15
\end{tabular}

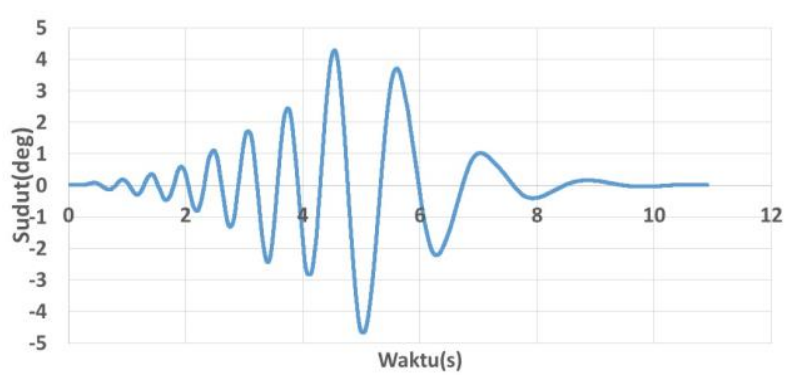

Gambar 2. Grafik gerakan wavemaker pada simulasi numerik $S P H$.

Pada Gambar 2. Menunjukkan grafik hubungan gerakan flap pembangkit gelombang terhadap waktu. Pembangkit gelombang di simulasi numerik ini bergerak berdasarkan prescribe motion yang diberikan pada flap sehingga gerakan flap mengikuti grafik pada Gambar 2. DualSPHysics sendiri memiliki fasilitas pembangkit gelombang secara otomatis baik untuk gelombang regular maupun irregular.

\section{HASIL DAN PEMBAHASAN}

Hasil simulasi numerik SPH untuk validasi gelombang telah memperlihatkan akurasi yang cukup akurat [7] dan pada kasus ini SPH memperlihatkan hasil yang akurat. Wave probe 1 dan wave probe 2 yang diletakan di posisi $1.16 \mathrm{~m}$ dan $2.66 \mathrm{~m}$ di depan pembangkit gelombang menunjukkan hasil yang sama dengan eksperimen ini diperlihatkan pada Gambar 3. Hal ini menunjukkan bahwa gelombang yang dihasilkan dari simulasi numerik $S P H$ memiliki akurasi yang akurat dan model numerik ini telah tervalidasi.

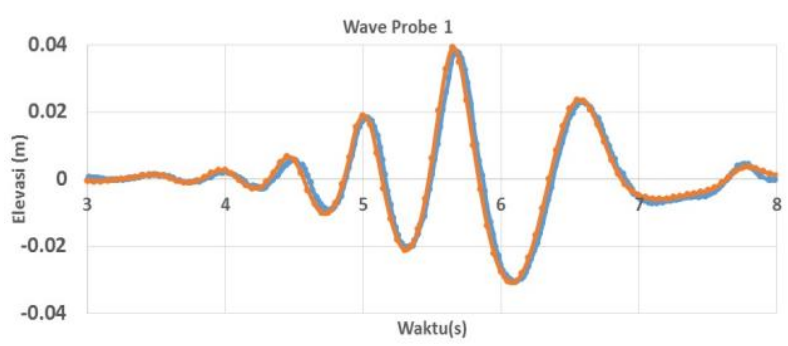




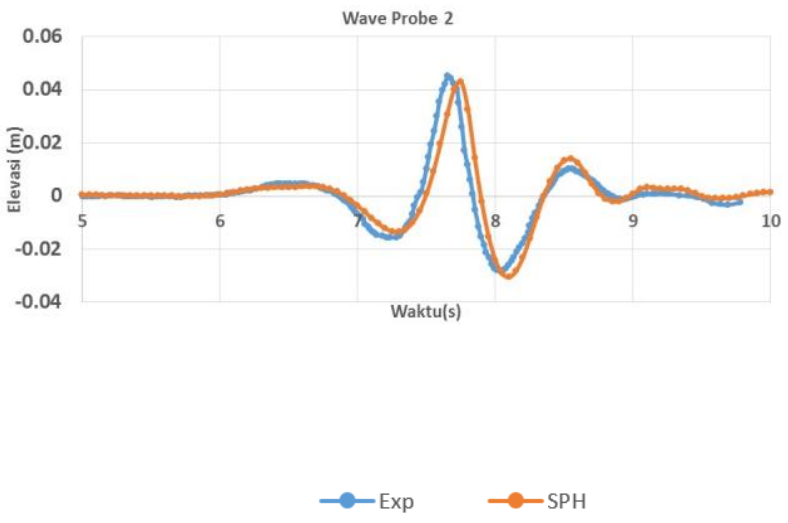

Gambar 3. Perbandingan hasil $S P H$ dengan eksperimen.

Berdasarkan Gambar 3. memperlihatkan bahwa gelombang dari simulasi numerik $S P H$ tidak terdapat beda phase. Tinggi gelombang juga memiliki hasil yang sama dengan eksperimen dan kecepatan rambat gelombang juga memiliki kesamaan dengan eksperimen ini diperlihatkan dari grafik gelombang berhimpit satu sama lain pada Gambar 3. Bentuk gelombang juga dapat diprediksi oleh $S P H$ meskipun bentuk gelombang jauh dari bentuk sinusoidal/nonlinier ini menunjukkan bahwa $S P H$ memiliki akurasi tinggi dilihat dari propertis gelombang. Berdasarkan Gambar 3. Menunjukkan bahwa gelombang yang terjadi memiliki tinggi gelombang yang sama antara kondisi wave probe $\mathrm{ke}-1$ dan $\mathrm{ke}-2$, ini menunjukkan bahwa perambatan gelombang di model numerik memiliki kesamaan dengan fenomena fisik dimana kekekalan energi juga terpenuhi oleh model numerik. effek dari gesekan antara fluida dan dinding sangat kecil seperti fenomena fisik akibatnya gelombang tidak mudah menghilang(decay). Hal ini menjadi salah satu alternatif untuk pemodelan gelombang di model numerik menggunakan SPH sebagai alternatif maupun pelengkap analisa eksperimen.

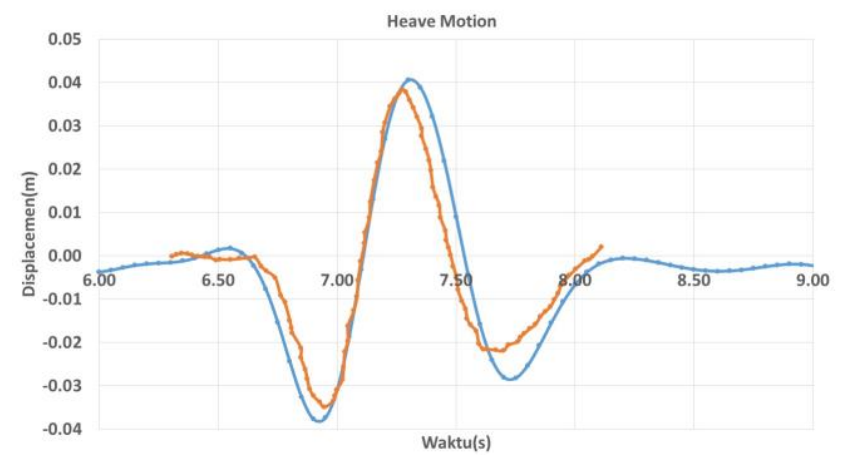

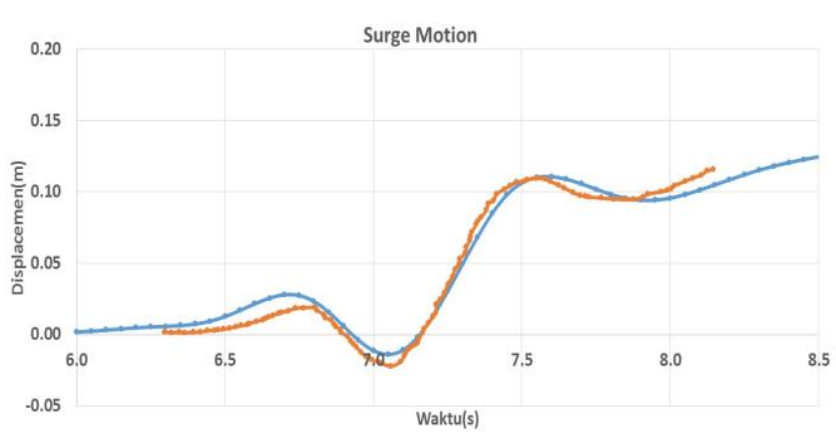
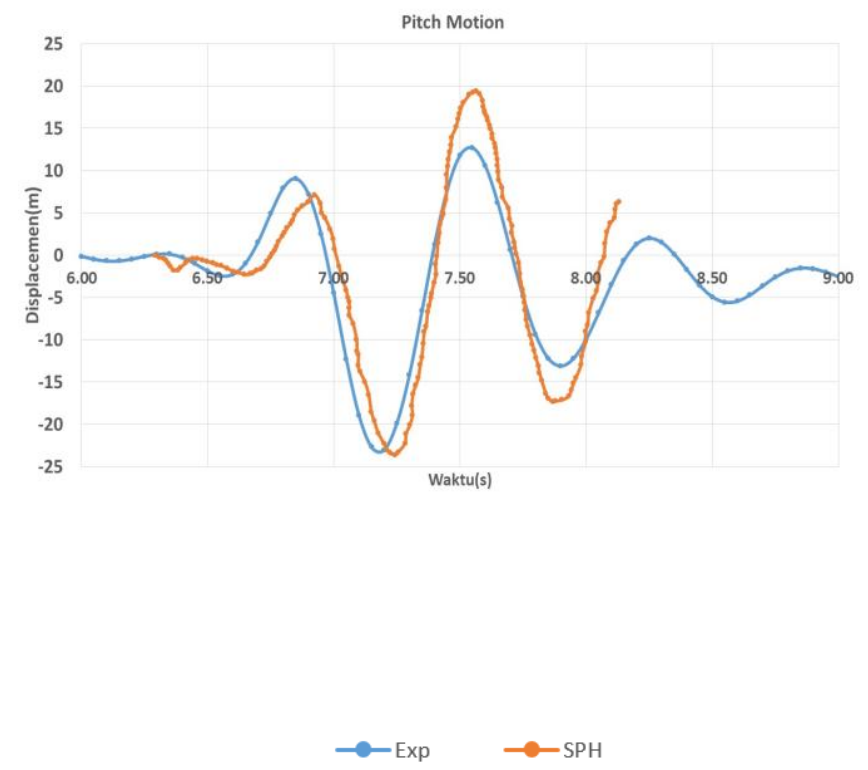

Gambar 4. Perbandingan hasil SPH dengan eksperimen untuk 3 DoF

Hasil dari simulasi numerik $S P H$ untuk gerakan benda terapung ditunjukkan pada Gambar 4. grafik gerakan benda terapung dari posisi diam hingga terkena gelombang hingga ke posisi statis kembali. Untuk gerakan translasi surge dan heave menunjukkan akurasi yang bagus ini diperlihatkan pada grafik gerakan heave meskipun terdapat shift yang kecil namun besaran amplitudo gerakannya memiliki besaran yang sama besar dengan eksperimen dan bentuk grafik gerakan memperlihatkan tren yang sama dengan hasil eksperimen. Gerakan surge memperlihatkan hasil yang lebih baik dibanding heave ini terlihat dari grafik gerakan surge simulasi numerik sama dengan eksperimen baik dari trend grafik maupun besaran gerakannya. Pada gerakan surge terlihat perpindahan benda/ gerak translasi tidak terlalu signifikan dikarenakan gelombang hanya dibangkitkan untuk sekali periode sehingga benda tidak hanya mengalami perpindahan yang kecil.

Gerakan heave memiliki perpindahan yang signifikan dan berdasarkan Gambar 3. 
menunjukkan puncak elevasi gelombang sebesar $0.04 \mathrm{~m}$ sehingga perbandingan hasil gerak heave pada Gambar 4. mengkonfirmasi hasil tersebut. Hasil ini memperlihatkan SPH memiliki akurasi yang tinggi dan memperlihatkan analisa interaksi fluida dan struktur dapat teratasi dengan mudah dengan metode ini.

Gerakan pitch dari simulasi numerik $S P H$ menunjukkan trend yang sama dengan eksperimen namun memiliki hasil yang lebih besar besaran

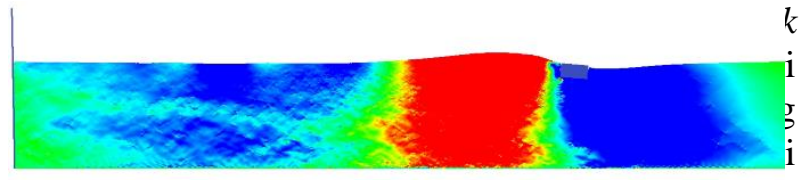

overestımate namun trend gerakan memil1k1 hasıl yang sama dengan hasil eksperimen. Ini terlihat periode gerakan benda memiliki kesamaan dengan hasil dari eksperimen baik pada saat pucak (peak) maupun setelah benda kembali keposisi diam/statis. Berdasarkan hasil tersebut simulasi numerik $S P H$ mampu memprediksi gerakan rotasi akibat dari hempasan gelombang. Pada simulasi ini input pada benda terapung hanya menggunakan relative weight yaitu perbandingan massa jenis benda dengan massja jenis air sehingga dengan input yang lebih spesifik akan memberikan hasil yang lebih baik seperti momen inersia, titik pusat berat dan inputan lainnya sehingga akan meningkatkan akurasi dari simulasi numerik.

Hasil simulasi numerik SPH menggunakan DualSPHysics untuk interaksi fluida dan struktur terapung memiliki akurasi yang tinggi ini diperlihatkan dari hasil gelombang yang tervalidasi dengan eksperimen dengan menggunakan dua wave probe yang di letakan pada posisi sebelum dan sesudah benda dan telah tervalidasi dengan eksperimen. Gerakan benda terapung yang dihempas oleh gelombang juga memperlihatkan hasil yang bagus ini terlihat dari Gambar 4. Pada kondisi ini gerakan benda meliputi tiga derajat kebebasan dimana gerakan pada vertikal lebih signifikan dibandingkan gerakan horisontal. DualSPHysics juga memiliki fasilitas post processing untuk menghasilkan file $v t k$ untuk dipergunakan di paraview sehingga memudahkan untuk melihat hasil simulasi numerik dan analisa lebih lanjut menggunakan post processing. Gambar 5. Memperlihatkan snapshot gerakan benda terapung terhempas oleh gelombang. Contour warna menunjukkan horizontal velocity pada saat kondisi diam hingga gelombang sebelum dan setelah melewati benda terapung.

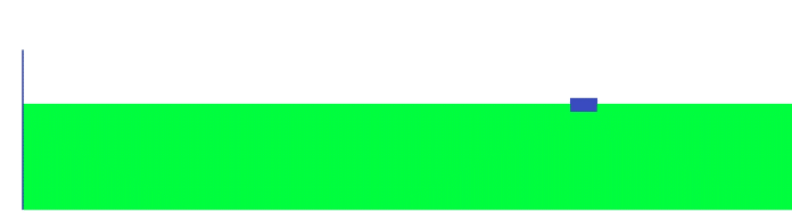

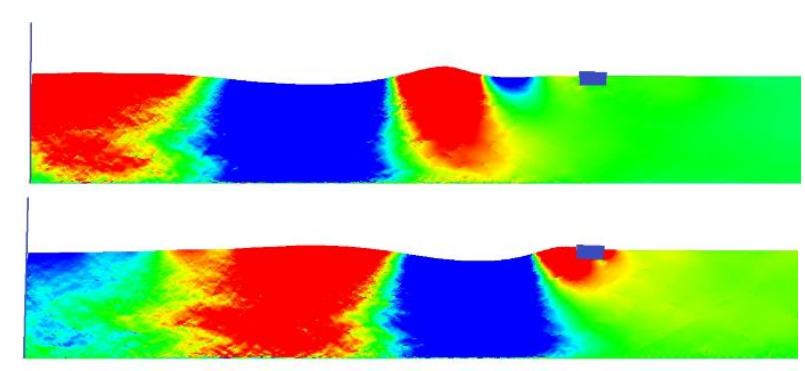

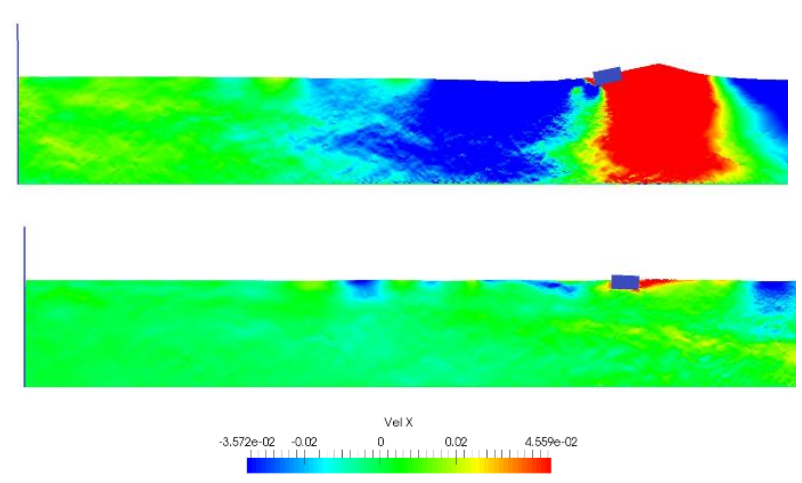

Gambar 5. Snapshot $S P H$ untuk t $=0.0$ s, 6.0 s, $6.5 \mathrm{~s}, 7.0 \mathrm{~s}, 7.5 \mathrm{~s}, 8.0 \mathrm{~s}$

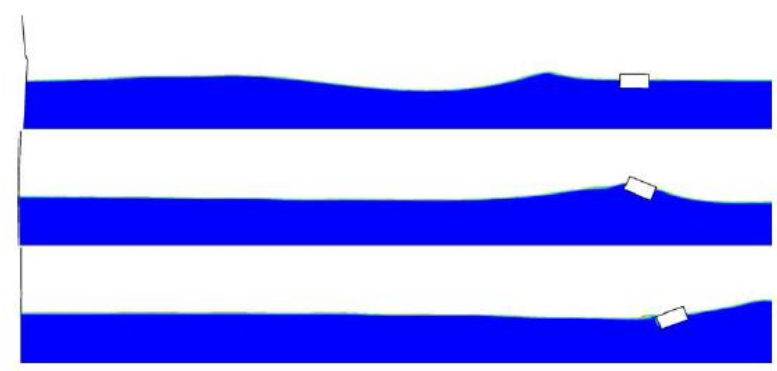

Gambar 6. Snapshot simulasi numerik hasil Hadz ic et al [8]

Berdasarkan perbandingan hasil simulasi numerik yang dilakukan oleh Hadz ic et al [8] menunjukkan trend yang sama ini diperlihatkan pada Gambar 6. Hasil ini menunjukkan bahwa SPH memiliki akurasi yang sama dengan metode mesh walaupun metode ini tergolong baru. Dibandingkan metode mesh yang telah maju dan mature metode partikel SPH baru berkembang dalam dua dekade ini, menunjukkan potensi penggunaan $S P H$ pada bidang teknik kelautan secara khusus maupun teknik pada umumnya. Selain keunggulan tidak adanya grid pada model ini, juga tidak perlunya teknik khusus untuk mendeteksi free surface sehingga metode ini memiliki kelebihan tidak perlunya mengenerate mesh yang sangat menyita waktu dalam pemodelan numerik. Data eksperimen dan hasil 
ini merupakan salah satu contoh kasus yang ada di program DualSPHysics.

\section{KESIMPULAN}

Bedasarkan hasil simulasi numerik $S P H$ menggunakan DualSPHysics ver 4.0 memperlihatkan bahwa untuk permasalahan interaksi fluida dan struktur terapung memperlihatkan akurasi yang baik dan telah tervalidasi menggunakan data eksperimen baik gerak heave, surge dan pitch memiliki akurasi yang bagus, dimana hasil dari pemodelan numerik $S P H$ telah divalidasi menggunakan data eksperimen dari studi sebelumnya .

Hasil studi ini memperlihatkan $S P H$ memiliki akurasi yang cukup baik untuk masalah interaksi fluida dan struktur namun perlunya dikembangkan untuk permasalahan yang lebih kompleks seperti menggunakan geometri kompleks seperti kapal. Perlunya studi lebih lanjut untuk permasalahan kompleks dalam tiga dimensi untuk aplikasi dalam bidang teknik secara umum.

\section{UCAPAN TERIMA KASIH}

Ucapan terima kasih ditujukan kepada kemenristekdikti untuk beasiswa BPP-LN dengan No. 181.47/E4.4/2014.

\section{DAFTAR PUSTAKA}

[1] J. J. Gingold, R.A, Monaghan, "Smoothed Particle Hydrodynamics: Theory and Application to Non-Spherical Stars," Mon.Not.R.ast.Soc, vol. 181, pp. 375-389, 1977.

[2] J. J. Monaghan, "Simulating Free Surface Flows with SPH," J. Comput. Phys., vol. 110, pp. 399-406, 1994.

[3] R. A. Dalrymple and B. D. Rogers, "Numerical modeling of water waves with the SPH method," Coast. Eng., vol. 53, no. 2-3, pp. 141-147, 2006.

[4] M. Antuono, A. Colagrossi, S. Marrone, and C. Lugni, "Propagation of gravity waves through an SPH scheme with numerical diffusive terms," Comput. Phys. Commun., vol. 182, no. 4, pp. 866-877, 2011.

[5] A. Barreiro, A. J. C. Crespo, J. M. Domínguez, and M. Gómez-Gesteira, "Smoothed Particle Hydrodynamics for coastal engineering problems," Comput. Struct., vol. 120, pp. 96-106, 2013.

[6] G. Pringgana, L. S. Cunningham, and B. D. Rogers, "Modelling of tsunami-induced bore and structure interaction," Proceeding Inst. Civ. Eng. Eng. Comput. Mech., vol. 169, pp. 109-125, 2016.

[7] A. Trimulyono, H. Hashimoto, and K. Kawamura, "Experimental Validation of SPH for Wave Generation and Propagation in Large Wave Tank," in Proceedings of the Twenty-seventh (2017) International Ocean and Polar Engineering Conference San Francisco, CA, USA, June 25-30, 2017, pp. 584-590.

[8] I. Hadz ic, J. Hennig and M. Peric, "Computation of flow-induced motion of floating bodies," vol. 29, pp. 1196-1210, 2005.

[9] A. J. C. Crespo et al., "DualSPHysics: Open-source parallel CFD solver based on Smoothed Particle Hydrodynamics (SPH)," Comput. Phys. Commun., vol. 187, pp. 204-216, 2015.

[10] D. Benedict, A. C. Crespo, J. M. Dominguez, A. Barreiro, and M. Go, "GPUs, a New Tool of Acceleration in CFD : Efficiency and Reliability on Smoothed Particle Hydrodynamics Methods," vol. 6, no. 6, 2011.

[11] A. J. C, Crespo, Gómez-Gesteira M and R. A. Dalrymple. 2007. Boundary conditions generated by dynamic particles in SPH methods. Computers, Materials \& Continua, 5, 173-184. 